\title{
Research on Spatial-temporal Changes and its Driving Force of Land use in the Yellow River Delta
}

\author{
WANG Wei \\ Water Resources Research Institute of Shandong Province, Jinan 250013, China \\ Shandong Provincial Key Laboratory of Water Resources and Water Environment, Jinan 250013, China \\ WANG Xin, Huang Qin \& Sun Li \\ Water Resources Research Institute of Shandong Province, Jinan 250013, China
}

\begin{abstract}
As the most potential big river delta, the Yellow River Delta has distinct land resource advantages, good location and abundant natural resources. In this paper, we regarded Dongying City as the study area and analyzed the spatiotemporal characteristics of land use from1992 to 2010 in this area. As well as we explored the socioeconomic factors and driving force of human activities which cause the land use change. The research result shows: (1) The overall trend is that building land, water body, salt pan and forest area is increasing, while the arable land, intertidal zone, grassland and unused land is decreasing. Of which, building land increased by $5.92 \%$; (2) The study area mainly switch among cultivated land, building land and salt pan. There were $355.79 \mathrm{~km} 2$ arable land become building land, $225.75 \mathrm{~km} 2$ intertidal zone became salt pan. The conversion between cultivated land, salt pan, building land and water body occurred frequently; (3) The number of eight kinds of land plaque was reduced to 32,892 from 51,650. And seven landscape indicators in arable land were reduced; (4) The analysis of driving factor in land-use change of the research area showed that: human activities is changing the overall pattern of land utilization in the area; policy guidance is the macro factor to impact land-use change in the area; while the rising population and rapid urbanization are the direct driving force to a significant reduction of arable land.
\end{abstract}

KEYWORD: Land Use; Temporal-spatial Changes; Driving Force; Yellow River Delta

\section{INSTRUCTIONS}

With prominent spatiality and temporality as its characteristics, land utilization is a truly mirror of human activities based on nature. Since 1980s, the comprehensive study on land use and land cover issues had become a new research hotspot as well as an advanced topic of global environmental change and the earth systematic science. By way of remoter sensor and GIS technology, however, the study on land-use change has uncovered its rule of spatialtemporal variations and its driving mechanism, which have become the newest trend of current researches.

Choosing Dongying City as the research area, on the basis of data from remote sensing of land resource, we divide the land-use type in Dongying with the support of $3 \mathrm{~S}$ technology and use TM imagery as information source. We adopt transfer matrix and landscape metrics method to analyze the spatialtemporal feature of the regional land-use change. Combined with the statistic data, we will further study the social and economic factors that caused land-use change and the human driving force. This paper can also be used as a reference to the rational exploitation, efficient cultivation, optimal allocation, effective protection and comprehensive management of land resource in the Yellow River Delta. At the same time, this paper may provide some theoretical support to the successful implementation of national strategic on the Yellow River Delta's high-efficiency ecological economic zone.

\section{GENERAL SITUATION ABOUT THE STUDY AREA}

As the greatest potential river delta in exploitation, Yellow River Delta has distinct advantage in land resource, favorable conditions of geographical location and abundant natural resource. It is one of the important areas in Shandong Province to keep dynamic equilibrium of the total cultivated land and enlarge arable lands. The main area situated in Dongying, Shandong Province, which appears as a fan-shaped triangle. Located between $118^{\circ} 05^{\prime \prime} \sim$ $119^{\circ} 18^{\prime} \mathrm{E}$ and $36^{\circ} 55^{\prime} \sim 38^{\circ} 16^{\prime} \mathrm{N}$, the total area is $13230.8 \mathrm{~km} 2$. On account of the integrity of administrative region, this paper regard Dongying City as the representative area in Yellow River Delta (Dongying covers 93\% of the Yellow River Delta acreage). 


\section{DATA SOURCES AND RESEARCH METHODS}

\subsection{Data sources}

The pictures mainly from the resource and environment database of CAS(China Academy of Science), Landsat TM imagery in 1992 and Landsat ETM multispectral remote sensing imagery in 2010. All these pictures are of good quality. In order to possess the remote sensing imagery and explain the change in land use and cover, we collect the present map of land utilization, the topographic map, the administrative map and some materials about the land-use type of relevant years. Moreover, information such as the drying up of the Yellow river, meteorological data, natural disaster and social economy materials are also covered.

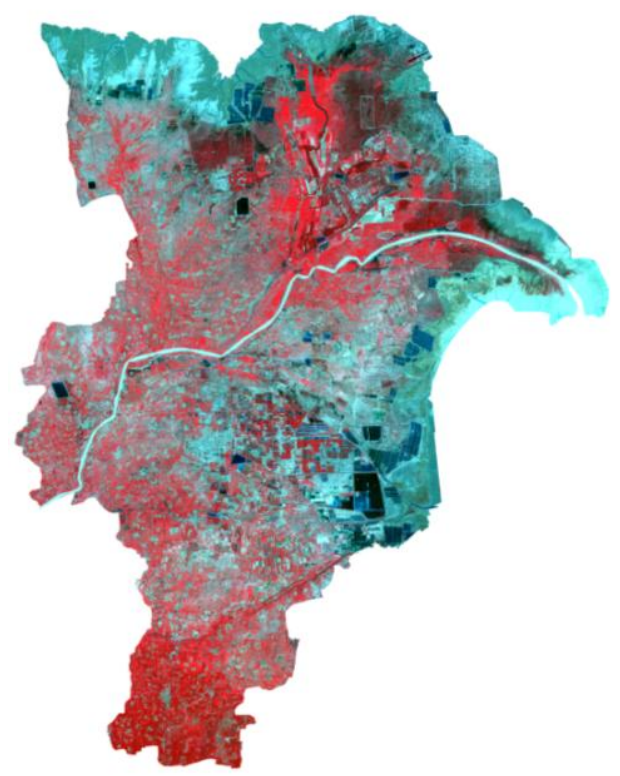

Fig.1(a)(1992)

\subsection{Classification scheme of land-use type}

Referring to the national land classification system enacted by Ministry of Land and Resource, we divide the study area into 8 main types of land utilization by the ArcGIS93 software based on the land-use features in Dongying and spatial resolution of TM remote sensing imagery. They are cultivated land, forest land, grass land, water body, construction land, intertidal zone, salt pan and unused land. According to the data statistical characteristics of each band and the visual analysis of synthesis effects, we choose the TM4、3、2、 band which is sensitive to vegetation to conduct RGB false color composite(see fig.1). We adopt the remote sensing imagery classification method of object-oriented to extract classification of land-use type and information in different periods (see fig.2).

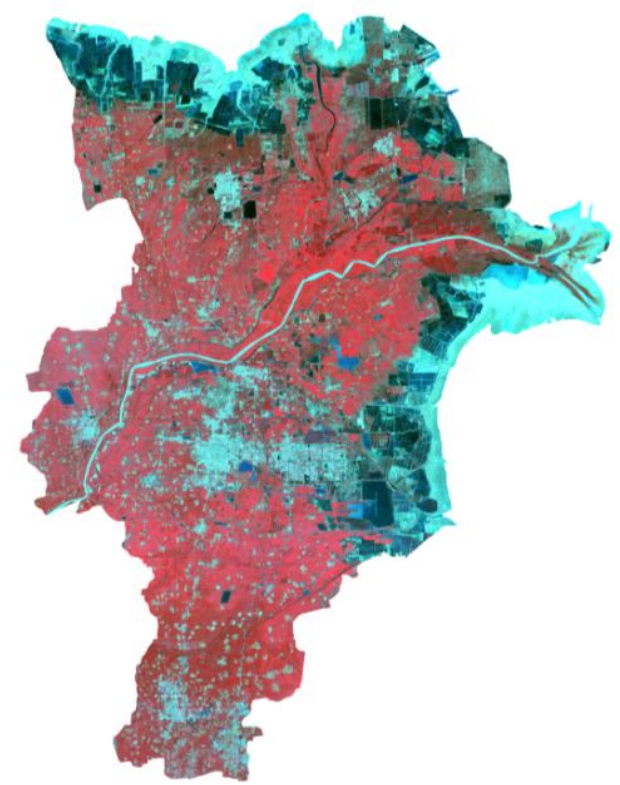

Fig.1(b)(2010)

Fig.1 Color composite image before enhancement of Dongying City

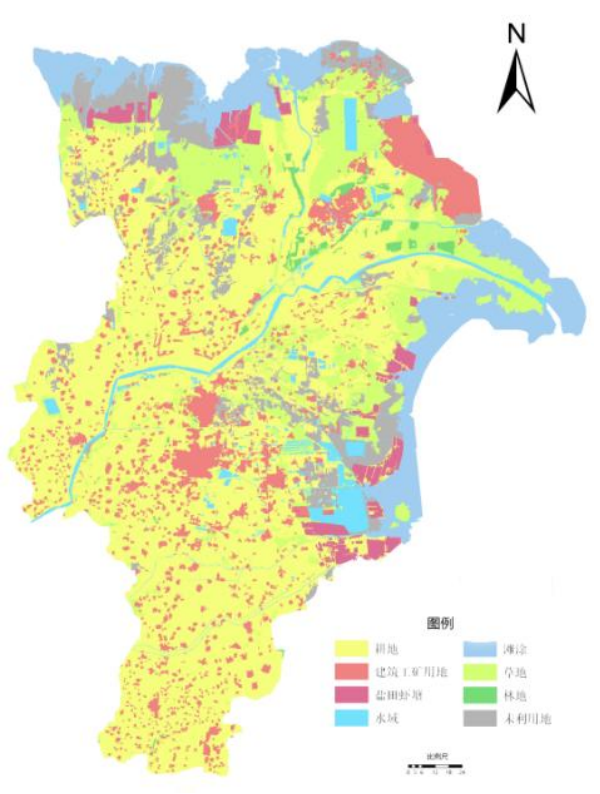

Fig.2(a)(1992)

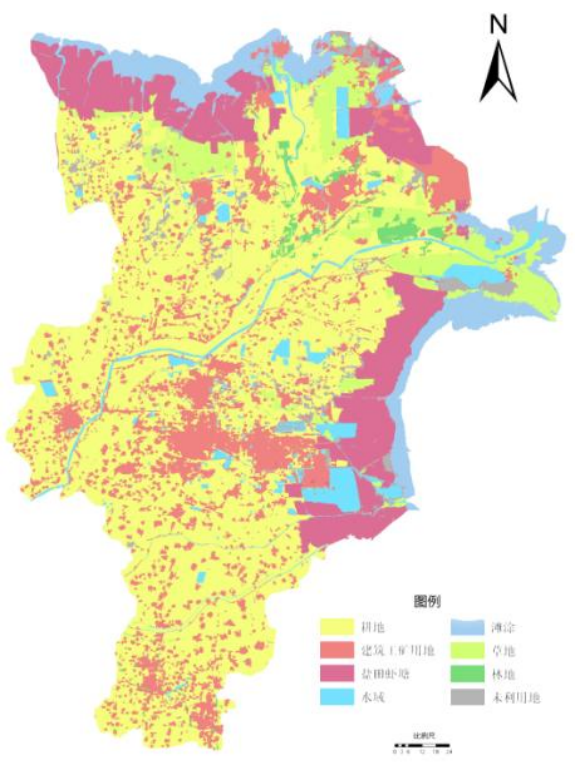

Fig.2(b)(2010)

Fig.2 Classification result of land use types of Dongying City 


\subsection{Land-use transfer matrix}

In the ARCVIEW3.2 spatial analysis modules, the distribution diagram of land-use grid in 1992 and 2010 were overlaid through Map Calculator. In the property management module, the connection was established between landscape overlay chart and EXCEL files. The conclusion of overlay analysis would be exported into EXCEL sheets. And with the help of the statistical function of EXCEL, conversion matrix among land-use type in 1992 2010 can be obtained.

\subsection{Select and extract of landscape index}

This paper is based on FRAGSTATS33 version of WINDOWS, which has friendly interfere and the ARC/INFO or ARCVIEW as its basic working environment and supports a variety of vectors and grid data of various forms such as ARC/INFO、

IDRISI、ERDAS etc. By editing the picture of land classification result and format conversion, accurate grid data with $30 \mathrm{~m} \times 30 \mathrm{~m}$ can be got, then collect landscape index of each tier. Based on the land resource features of the Yellow River Delta, we chose seven landscape indexes with guaranteed calculating accuracy: plaque number, fractal dimension, patch density, patch separation, maximum patch index, landscape shape index, landscape aggregation index.

\section{SPATIAL-TEMPORAL CHANGE OF LAND UTILIZATION}

\subsection{The areas of land-use type in different times}

As shown in table1, during the past two decades, the spatial pattern of land utilization in Dongying City had undergone great changes. Building land, water body, salt pan and forest land were all on the increase ever since. Accounting for $11.11 \%$ of the acreage, building land covered an area of $880.87 \mathrm{~km}^{2}$ in 1992; while it increased by $469.62 \mathrm{~km}^{2}$ to $1350.49 \mathrm{~km}^{2}$ in 2010 , occupying $17.04 \%$ of the acreage. Besides, the remarkably expansion of building land indicated that urbanization was escalating without stop. With regard to salt pan, the growing rate reached $9.53 \%$.

Table1 Land use type and area in Dongying City from 1992 to 2010

\begin{tabular}{|c|c|c|c|c|c|c|}
\hline \multirow{2}{*}{ Land Types } & \multicolumn{2}{|c|}{1992} & \multicolumn{2}{|c|}{2010} & \multicolumn{2}{c|}{$1992-2010$} \\
\cline { 2 - 7 } & Area $\left(\mathrm{km}^{2}\right)$ & Percent $(\%)$ & Area $\left(\mathrm{km}^{2}\right)$ & Percent $(\%)$ & Area $\left(\mathrm{km}^{2}\right)$ & Percent $(\%)$ \\
\hline Cultivated land & 3986.08 & 50.28 & 3966.75 & 50.04 & -19.33 & -0.24 \\
\hline Building land & 880.87 & 11.11 & 1350.49 & 17.04 & 469.62 & 5.92 \\
\hline Forest Land & 67.07 & 0.85 & 102.06 & 1.29 & 34.99 & 0.44 \\
\hline Water body & 327.54 & 4.13 & 372.31 & 4.70 & 44.77 & 0.56 \\
\hline Mud flat & 738.53 & 9.32 & 388.28 & 4.90 & -350.25 & -4.42 \\
\hline Salt pan & 209.1 & 2.64 & 964.79 & 12.17 & 755.69 & 9.53 \\
\hline Grassland & 1053.84 & 13.29 & 563.15 & 7.10 & -490.69 & -6.19 \\
\hline Unused land & 664.17 & 8.38 & 219.36 & 2.77 & -444.81 & -5.61 \\
\hline Sum & 7927.2 & 100.00 & 7927.2 & 100.00 & - & - \\
\hline
\end{tabular}

\subsection{Transfer matrix of land use types}

As shown in table 2, the land use types of Dongying city are in course of continuous change over the last 20 years. The conversions of land use types are frequent among grassland, salt pan, building land and water body. Among them, $355.79 \mathrm{~km}^{2}$ of cultivated lands convert into building land and $225.75 \mathrm{~km}^{2}$ of mud flat convert into salt pan from 1992 to 2010. The result shows that conversions of land use types are related to the unreasonable land use of the study area. In addition, the conversion of cultivated land is related to the water resource abundance and the lack of fresh water leads to the conversion from cultivated land to salt pan.

\subsection{Analysis on the change of landscape pattern in land utilization}

As can be seen from Diagram3: During the past two decades, the number of eight land patches in Dongying City had reduced from51650 to 32892. What's more, all the seven landscape index were cut down. The proportion of patch area in building land to gross area increased by $5.91 \%$; patches reduced by 3798 with lessening density. And the biggest patch index improved from 1.9017 to 3.1402; meanwhile, its landscape shape index improved either. 
Table2 Transfer matrix of land type and area change from 1992 to 2010 in Dongying City $\left(\mathrm{km}^{2}\right)$

\begin{tabular}{|c|c|c|c|c|c|c|}
\hline \multirow{2}{*}{ Land Types } & \multicolumn{2}{|c|}{1992} & \multicolumn{2}{|c|}{2010} & \multicolumn{2}{|c|}{$1992-2010$} \\
\hline & Area $\left(\mathrm{km}^{2}\right)$ & Percent $(\%)$ & Area $\left(\mathrm{km}^{2}\right)$ & Percent $(\%)$ & Area $\left(\mathrm{km}^{2}\right)$ & Percent $(\%)$ \\
\hline Cultivated land & 3986.08 & 50.28 & 3966.75 & 50.04 & -19.33 & -0.24 \\
\hline Building land & 880.87 & 11.11 & 1350.49 & 17.04 & 469.62 & 5.92 \\
\hline Forest Land & 67.07 & 0.85 & 102.06 & 1.29 & 34.99 & 0.44 \\
\hline Water body & 327.54 & 4.13 & 372.31 & 4.70 & 44.77 & 0.56 \\
\hline Mud flat & 738.53 & 9.32 & 388.28 & 4.90 & -350.25 & -4.42 \\
\hline Salt pan & 209.1 & 2.64 & 964.79 & 12.17 & 755.69 & 9.53 \\
\hline Grassland & 1053.84 & 13.29 & 563.15 & 7.10 & -490.69 & -6.19 \\
\hline Unused land & 664.17 & 8.38 & 219.36 & 2.77 & -444.81 & -5.61 \\
\hline Sum & 7927.2 & 100.00 & 7927.2 & 100.00 & - & - \\
\hline
\end{tabular}

Table3 Landscape patterns indexes of different land type from 1992 to 2010 in Dongying City

\begin{tabular}{|c|c|c|c|c|c|c|c|c|}
\hline Period(Year) & TYPE & PLAND & NP & PD & LPI & LSI & PAFRAC & COHESION \\
\hline \multirow{8}{*}{1992} & Cultivated land & 47.8667 & 778 & 0.1019 & 22.7535 & 1.4561 & 426.431 & 0.4232 \\
\hline & Building land & 11.9248 & 10959 & 1.4357 & 1.9017 & 1.1238 & 665.0133 & 0.1539 \\
\hline & Forest Land & 1.4353 & 10423 & 1.3654 & 0.1132 & 1.0859 & 732.8232 & 0.0688 \\
\hline & Water body & 4.1708 & 8240 & 1.0795 & 0.9216 & 1.1151 & 697.6552 & 0.105 \\
\hline & Mud flat & 10.7411 & 7871 & 1.0311 & 4.0863 & 1.0625 & 735.943 & 0.0621 \\
\hline & Salt pan & 3.0135 & 9151 & 1.1988 & 0.2673 & 1.079 & 726.777 & 0.0739 \\
\hline & Grassland & 12.7652 & 3900 & 0.5109 & 2.185 & 1.1628 & 673.435 & 0.1372 \\
\hline & Unused land & 8.0826 & 328 & 0.043 & 1.7417 & 1.7509 & 315.2391 & 0.5744 \\
\hline \multirow{8}{*}{2010} & Cultivated land & 47.1945 & 677 & 0.0879 & 19.6991 & 1.4117 & 423.9087 & 0.4223 \\
\hline & Building land & 17.8314 & 7161 & 0.9299 & 3.1402 & 1.2125 & 598.4941 & 0.2313 \\
\hline & Forest Land & 1.7345 & 7540 & 0.9791 & 0.2915 & 1.117 & 711.1901 & 0.0912 \\
\hline & Water body & 4.6877 & 4662 & 0.6054 & 0.7 & 1.1337 & 693.8551 & 0.1099 \\
\hline & Mud flat & 6.8596 & 4836 & 0.628 & 2.2037 & 1.0956 & 718.5712 & 0.0798 \\
\hline & Salt pan & 12.0865 & 4473 & 0.5809 & 3.8048 & 1.0896 & 715.1099 & 0.0842 \\
\hline & Grassland & 7.1335 & 2815 & 0.3656 & 1.6989 & 1.1202 & 695.034 & 0.11 \\
\hline & Unused land & 2.4723 & 728 & 0.0945 & 0.3325 & 1.5387 & 351.214 & 0.5165 \\
\hline
\end{tabular}

\section{DRIVING FORCE ANALYSIS}

Land-use change is mainly influenced by natural and human activities, but in a short period, the latter is undoubtedly the most important driving factor. Under certain natural condition, it is the socioeconomic factor, technical factor and policies and regulations that determine the direction, structure, size, layout and approach of land exploitation and utilization. Therefore, to analyze the relationship between these factors and land utilization is of great importance to establish a reasonable land planning.

\subsection{Policy orientation}

Since 1988 , the State and Shandong Province paid much value to the exploitation of Yellow River Delta; In 1992 , the Shandong provincial government makes the Yellow River Delta as one of its two major trans-century projects to promote provincial economy to become strong from large; In 1993, Dongying City was approved by the State Council as an open coastal economic zone; In 1994 , the United Nations Development Program makes "sustainable development of the Yellow River" the first priority project to implement, as a means to support "China's Agenda of 21st Century"; In 2001, "Yellow River Delta's efficient Eco-Economic development" was included in the tenth national five-year plan outline; In 2006, it was included in the eleventh national five-year individual plan by National development and Reform Commission. As a result, the development of Yellow River Delta leapt to a higher platform; until 2009, the State Council officially approved the "Development program of Yellow River Delta's efficient ecological economic zone". 


\subsection{Population and economy composition}

During the past two decades, the population of Dongying City had kept a good momentum. Taken the registered population into consideration alone, the city's total population has reached from 156.93 million in 1990 to 184.87 million in 2010, an average annual increase of 13,300 people. Meanwhile, the population and economy composition had significant changes. In 1990, agricultural population accounts for up to $78.44 \%$ of the total population. By 2010, it had already dropped to $56.3 \%$. The net growth in population and the change in its economic constitution, making more and more people concentrated on cities and towns, which upgrades the demand for living space. In the end, large tracts of farmland turned into urban construction land and the arable land were on the decline year by year.

\subsection{The scale and structure of social economy}

The socio-economic scale reflects the volume of human activity. Correspondingly, rapid economic growth means more frequent human activities. The socio-economic scale in Dongying City has been growing rapidly. According to price estimates, GDP has increased from 6.574 billion yuan in 1990 to 235.994 billion yuan in 2010, an average annual growth rate of $17.6 \%$. Of which, the primary industry increased at an average annual growth of $13.6 \%$, the secondary industry was $17.1 \%$, and the tertiary industry was $22.4 \%$. Also, the structure of the three industries has gradually developed into 3:73:24 from 13:78:9 by the end 1990. From 1984 to 1999 , with an average annual area growth rate of $8.18 \%$, Shengli Oil Field formed a dense oilfield building zone, occupying a lot of surrounding farmlands. On the other hand, it made the surrounding ecological environment more fragile; after 2000, although the expansion was slowing down, the surrounding farmland was still under huge pressure.

\section{CONCLUSION}

(1) From 1992 to 2010, the land-use structure in the study area changed greatly. The overall trend is that building land, water body, salt pan and forest area is increasing, while the arable land, intertidal zone, grassland and unused land is decreasing. Of which, building land increased by $5.92 \%$.

(2)During 1992-2010, the study area mainly switches among cultivated land, building land and salt pan. There were $355.79 \mathrm{~km} 2$ arable land become building land, $225.75 \mathrm{~km} 2$ intertidal zone became salt pan. The conversion between cultivated land, salt pan, building land and water body occured frequently.
(3) From 1992 to 2010, the number of eight kinds of land plaque was reduced to 32,892 from 51,650. And seven landscape indicators in arable land were reduced.

(4) The analysis of driving factor in land-use change of the research area showed that: human activities is changing the overall pattern of land utilization in the area; policy guidance is the macro factor to impact land-use change in the area; while the rising population and rapid urbanization are the direct driving force to a significant reduction of arable land.

\section{REFERENCES}

[1] WANG Si-Yuan, ZHANG Zeng-Xiang, ZHOU QuanBin, LIU Bin, WANG Chang-You; Analysis of landscape patterns and driving factors of land use in China; ACTA ECOLOGICA SINICA , 2003,23(4):649-656.

[2] YANG Wen-Xuan, PANG Hong-Li, ZHANG Xu; Analysis on Dynamic Change of Land Use in Lanzhou City during Recent 10 Years; Research of Soil and Water Conservation, 2013, 20(6):231-236.

[3] ZHANG Hai-long, JIANG Jian-jun, XIE Xiu-ping, WU Hong-an, ZHANG Li; Analyzing Land Use Changes and Its Driving Forces in Xi'An Region During the Past 25 Years; RESOURCES SCIENCE, 2006,28(4):71-77.

[4] Bai Yuan, Xu Hailiang, Liu Xinhua, Ling Hongbo, Zhao Xinfeng; DYNAMIC CHANGE IN CULTIVATED LAND AND LANDSCAPE PATTERN ALONG THE MAINSTREAM OF THE TARIM RIVER; Acta Pedologica Sinica, 2013,50(3):492-500.

[5] LIU Baoxiao, HUANG Yaohuan, FU Jingying, JIANG Dong; Analysis on Spatio-temporal Change and Driving Forces of Land Use in Tianjin Harbor; Journal of GeoInformation Science, 2012,14(2):270-278.

[6] QI Yang, WU Jiangguo, LI Jianlong, YU Yang, PENG FUli, SUN Chong; Landscape dynamics of medium-and small-sized cities in eastern and western China:a comparative study of pattern and driving forces; Acta Ecologica Sinica, 2013,33(1):275-285.

[7] LI Xinju, HU Zhenqi, LIU Ning, YU Kaiqin, MA Xiaoyou; Research of soil quality based on $3 \mathrm{~S}$ in the Yellow River delta; TRANSACTIONS OF THE CHINESE SOCIETY OF AGRICULTURAL ENGINEERING, 2005, 21(10):59 63.

[8] WANG Ai-ling, ZHAO Geng-xing, WANG Rui-yan, YUAN Xiang-ming; Quality Evaluation for Regional Farmland Consolidation and Spatio-temporal CollocationA Case Study in Qingzhou County, Shandong Province of China; JOURNAL OF NATURAL RESOURCES, 2006, 21(3):369 374.

[9] WANG Wei, CHEN Weifeng; Study on Integrated Ecological Evaluation Land Consolidation in Yellow River Delta: A Case Study in Kenli County; China Land Science, 2008,22 (1):65-70.

[10] WANG Wei, CHEN Wei-feng, WANG Ran-li, GAN Yun-xian; Landscape Pattern Characteristic and Dynamic Change of Newborn Wetland in the Yellow River Delta-A Case Study in Kenli County; RESEARCH OF SOIL AND WATER CONSERVATION, 2010, 17(1):33-38. 